\title{
A INFORMAÇÃO INFORMAL E A MONITORAÇÃO DO AMBIENTE: FONTES E EXPLORAÇÃO/ DISSEMINAÇÃO
}

\author{
Informal information and the environmental \\ scanning activity:sources and processing/ \\ dissemination ategies
}

Envio ??.??.?? / Aceite ??.????

\section{Fernando Kuhn Andriotti ${ }^{1}$ Henrique Freitas ${ }^{2}$}

\begin{abstract}
Resumo
Dentre todas as atividades que uma organização realiza, a monitoração do ambiente certamente deveria ser uma delas. Essa atividade, que tem como principal entrada [e também saída] a informação, raramente é corretamente desenvolvida. Muitos são os fatores que a influenciam e um deles é o excesso de informação disponível no mercado, o que dificulta a monitoração, levando os indivíduos a recorrerem a informações não-estruturadas, informais, provenientes das mais diversas fontes. O objetivo deste artigo é buscar compreender, por meio da identificação de algumas dimensões da atividade de monitoração do ambiente, o uso da informação informal por executivos da área de TI. Por se tratar de um estudo de natureza
\end{abstract}

${ }^{1}$ Graduado em Administração pela UFRGS (2004), mestre em Administração (PPGA/EA/UFRGS) e doutorando no PPGA/EA/UFRGS. E-mail: fernando@kuhn.com.br.

${ }^{2}$ Doutor em Gestão (França), Professor Associado 2 PPGA/EA/UFRGS, Pesquisador CNPQ. E-mail: hf@ea.ufrgs.br. 
exploratória e qualitativa, a coleta de dados foi realizada por meio de entrevistas em profundidade com executivos da área. Os resultados, analisados à luz das dimensões identificadas, permitiu que se obtivesse um panorama do uso da informação informal na monitoração do ambiente.

Palavras-chave: Monitoração do ambiente; Informação informal; Fontes de informação; Inteligência no negócio.

\begin{abstract}
Among all activities that an organization carries out, environmental scanning certainly should be one of them. This activity which has information as the main input (and output as well) rarely is developed with all stages recommended. There are many reasons that influence this organizational behavior; one of them is the overflow of information, which interferes in the scanning activity. Because of this, many managers appeal to informal and non-structured information from different sources. Thus, the aim of this paper is to understand, through the identification of a few environmental scanning activity dimensions, the use of informal information by managers of IT area, that were selected according to the orientation of their organizational activities. This is an exploratory and qualitative study for that reason the data collection was made through interviews. The results, presented according to the dimensions, allowed having an overview of the use of informal information in the environmental scanning activity.
\end{abstract}

Keywords: Environmental scanning; Informal information; Sources of information; Business Intelligence.

\title{
1 Introdução
}

A informação, cada vez mais, tem se tornado um recurso imprescindível para organizações que desejam se manter no mercado. De acordo com Davenport (2001), cada vez mais informações estarão disponíveis e também será mais difícil estar informado sobre tudo que ocorre. O próprio indivíduo não consegue monitorar todo o seu ambiente, está além de sua capacidade (DAFT, SORMUNEN e PARKS, 1988), e o mesmo ocorre com as organizações.

Atentas à importância da informação, as organizações têm buscado sistematizar a tarefa de monitorar o seu ambiente, ou seja, de estarem informadas (SAPIRO, 1993). Esta monitoração caracteriza-se pela aquisição geral de informações de qualquer natureza, que possa ser utilizada nos diferentes processos da empresa, especialmente a tomada de decisão (FRISHAMMAR, 2002). No entanto, apesar dos avanços e das facilidades criadas pela Tecnologia da Informação (TI), seja no suporte às operações, seja na tomada de decisão ou, ainda, na busca e disponibilização de informação, certo tipo de dado, de interação, continua sendo estratégico para as organizações: os contatos informais (ANDRIOTTI e FREITAS, 2007).

Muitos executivos, incentivados por suas organizações, voltam-se para esses contatos não formais, no intuito de receber algo além do que é solicitado (KAYE, 1995a) e também para encurtar o ciclo de todo o processo, ou seja, tentar captar a informação diretamente, sem precisar realizar um esforço prévio de busca e seleção.

De acordo com Porter (1986), uma organização está sujeita a cinco forças diferentes, as quais podem influenciar todos os processos internos, inclusive a orientação para o futuro, são elas: (a) poder de barganha dos fornecedores, (b) ameaça de produtos substitutos, (c) poder de barganha dos clientes, (d) ameaça de novos entrantes e (e) rivalidade entre concorrentes. Assim, a organização que deseja se manter competitiva no mercado deve estar atenta ao que está 
ocorrendo, ou seja, monitorar constantemente essas forças em busca de sinais que possam, de alguma forma, ser utilizados para preparar a organização para futuras alterações no ambiente.

Com a TI, as distâncias, mais especificamente os mercados, ficaram, de certa forma, a um clique de mouse. Ou seja, rapidamente, através de um computador conectado à Internet, pode-se entrar em contato com diferentes pessoas e empresas, em diferentes localidades no mundo. Assim, a concorrência, que antes era um fator local de ameaça, passou a ser mundial.

O mesmo aconteceu para fornecedores e clientes, que podem estar nos mais diferentes locais. Com este cenário, a tarefa de monitorar o que acontece, aquilo que pode afetar a organização, cresceu, e muito, em complexidade. Acompanhando este crescimento de complexidade, a importância de se sistematizar a monitoração do que ocorre igualmente teve sua relevância potencializada.

O fluxo de informações proveniente desse ambiente competitivo, global, ganhou dimensões que, em muitas vezes, supera a capacidade do executivo de abstrair aquilo que é mais importante para a organização (COHEN, 2002). Diversas informações, diversos eventos, perturbações e sinais do ambiente sequer são notados, passam despercebidos entre o universo de informações que está à disposição. Eventos esses que podem ser ameaças à organização, mas, mais importante, que podem representar oportunidades que a organização está, de certa forma, ignorando.

Frente à dificuldade em considerar tudo aquilo que é disponibilizado, muitos recorrem a fontes informais, como amigos, conselheiros, entre outras. De acordo com Freitas e JanissekMuniz (2006), os métodos, técnicas e ferramental existente nem sempre permitem a gestão da informação informal, pouco estruturada, aleatória e essencialmente indeterminada.

Tendo em vista as considerações anteriores, entende-se que há uma latência desse tipo de informação, de difícil acesso, difícil formalização e que é, muitas vezes, ignorada pelos sistemas de informação corriqueiramente utilizados nas organizações, bem como pelos processos de monitoração do ambiente, tão fundamental no ambiente competitivo atual. Assim, o objeto de estudo deste trabalho é buscar compreender, no processo de monitoração do ambiente organizacional, as fontes de informações informais utilizadas para a monitoração do ambiente e a exploração e disseminação destas. Buscou-se, na medida do possível, identificar quais as fontes de informação informais que os executivos da área de TI mais utilizam para monitorar o ambiente e de que forma elas são exploradas/analisadas e disseminadas.

\section{A monitoração como ferramenta gerencial}

A monitoração do ambiente procura suprir o gerente com informações que sejam relevantes para o processo decisório, dando apoio às diferentes fases. De acordo com Drucker (2006, p. 23), "[...] a monitoração e a transmissão das informações têm de vir embutidas na decisão para facilitar verificações contínuas". Para Freitas et al. (1997, p. 28), a informação é "[...] elemento decisivo que pode determinar o êxito ou fracasso de um empreendimento". Conforme Aguilar (1967), mesmo que indiretamente, há uma dependência do processo de tomada de decisão da monitoração.

Uma das principais razões para que se desenvolva a atividade de monitoração do ambiente, de acordo com Albright (2004), é a natureza do ambiente de negócios atual, o qual está constantemente mudando e, com facilidade, deixa para trás as empresas que não se adaptarem a ele. Exatamente neste ponto que a monitoração do ambiente pode auxiliar os executivos, evitar que estes deixem de perceber sinais do ambiente que podem ser determinantes para a sobrevivência da organização. Neste contexto, Jain (apud COSTA, 1995, p. 5) ressalta que a 
atividade de monitoração do ambiente pode ajudar a organização de diversas formas, entre elas:

- ajuda a organização a aproveitar oportunidades;

- sinaliza para problemas iminentes;

- sensibiliza a organização para necessidades e desejos dos consumidores;

- provê uma base de dados qualitativa objetiva sobre o ambiente;

- fornece elementos para os tomadores de decisão;

- melhora a imagem da organização junto ao seu público ao demonstrar interesse por

este.

De acordo com Aguilar (1967), todas as empresas mantêm, de modo formal ou informal, algum mecanismo de monitoração do ambiente, de alguma forma as organizações estão atentas ao que ocorre no mercado. Em seus estudos, o autor chegou a quatro formas básicas de monitoração: observação indireta, observação condicionada, busca não-estruturada e busca estruturada. Uma breve descrição é dada a seguir:

A) OBSERVAÇÃO INDIRETA: é um modo de coleta de dados mais inconsciente, que, de certa forma, todas as organizações realizam, independentemente da estratégia definida. É o tipo de atividade que o executivo faz sem um propósito específico para a organização, a intenção é meramente estar informado sobre o todo. Este processo é altamente dependente da habilidade do gestor em captar essas informações. Faz uso de publicações, como jornais, revistas, informes, etc.;

B) OBSERVAÇÃO CONDICIONADA: nesta modalidade, a organização é mais consciente quanto ao seu ambiente e estabelece um modo formal de observação, contudo mais direcionada. Com uma lista predefinida de fontes a serem monitoradas, a organização estabelece critérios de seleção das informações coletadas. Normalmente faz uso de fontes escritas, como relatórios, base de dados e informes já consagrados por outras empresas do setor;

C) BUSCA NÃO-ESTRUTURADA: diferente dos dois modos acima apresentados, a busca por dados é uma atividade regular da organização e reconhecida como tal, no entanto, não é utilizada uma metodologia formal e estruturada nesta monitoração. Muitas vezes as empresas que estão classificadas neste grupo tentam influenciar o ambiente via estímulos para, então, observar o comportamento do mesmo;

D) BUSCA ESTRUTURADA: caracteriza-se por ser a maneira mais estruturada de monitoração do ambiente. Faz uso de diferentes fontes de informação, cada uma sendo observada com um propósito pré-definido. Esta é uma atividade formalmente representada dentro da organização, sendo um processo. Possui unidades de análise para dar sentido a tudo que é coletado, sempre obedecendo a metodologias previamente definidas e estruturadas.

De acordo com Choo (1999), uma organização, para ter sucesso em sua atividade de monitoração do ambiente, deve empreender todas as formas descritas por Aguilar (1967). A observação indireta ajuda a desenvolver uma visão periférica, o que permite ver e pensar de uma forma não tradicional. Já a observação condicionada busca tendências e pode sinalizar para eventos que ainda não ocorreram. Quando realiza uma busca não-estruturada, esta pode buscar compreender melhor um assunto (produto) que ainda está em desenvolvimento, permitindo identificar seu potencial impacto no ambiente. No que tange a busca estruturada, a organização tem acesso a todas as informações relevantes que permitam melhorar o processo decisório. 
No Quadro 1, é apresentada uma comparação entre as diferentes formas de monitoração do ambiente.

\begin{tabular}{|c|c|c|c|c|c|}
\hline $\begin{array}{c}\text { FORMA DE } \\
\text { MONITORAÇÃO }\end{array}$ & $\begin{array}{l}\text { NECESSIDADES } \\
\text { INFORMACIONAIS }\end{array}$ & $\begin{array}{c}\text { USO DA } \\
\text { INFORMAÇÃO }\end{array}$ & \begin{tabular}{|c|} 
ESFORÇO \\
EMPREGADO NA \\
ATIVIDADE
\end{tabular} & \begin{tabular}{|c|} 
NÚMERO \\
DE \\
FONTES
\end{tabular} & TÁT ICAS \\
\hline $\begin{array}{l}\text { Observação } \\
\text { indireta }\end{array}$ & Geral & $\begin{array}{l}\text { Descobertas } \\
\text { acidentais, de } \\
\text { assuntos não- } \\
\text { previstos }\end{array}$ & Mínimo & Muitas & $\begin{array}{l}\text { Monitorar diversas } \\
\text { fon tes, } \\
\text { aproveitand o o que } \\
\text { for fácil de ser } \\
\text { acessado }\end{array}$ \\
\hline $\begin{array}{l}\text { Observação } \\
\text { condicionada }\end{array}$ & $\begin{array}{l}\text { Permite reconhecer } \\
\text { tópicos de interesse }\end{array}$ & $\begin{array}{l}\text { Aumenta o } \\
\text { entendimento }\end{array}$ & Baixo & Algumas & $\begin{array}{l}\text { Procura, em fontes } \\
\text { pré-selecionadas, } \\
\text { tópicos pré- } \\
\text { selecionados }\end{array}$ \\
\hline $\begin{array}{l}\text { Busca não- } \\
\text { estruturada }\end{array}$ & $\begin{array}{l}\text { Permite formular } \\
\text { ações }\end{array}$ & $\begin{array}{l}\text { Melhora o } \\
\text { aprendizado, de } \\
\text { forma limitada }\end{array}$ & Moderado & Algumas & $\begin{array}{l}\text { Busca é focada em } \\
\text { um evento, sem } \\
\text { muita profundidade }\end{array}$ \\
\hline $\begin{array}{l}\text { Busca } \\
\text { estruturada }\end{array}$ & $\begin{array}{l}\text { Permite determinar } \\
\text { alvos }\end{array}$ & $\begin{array}{l}\text { Uso formal da } \\
\text { informação para } \\
\text { planejamento e } \\
\text { ação }\end{array}$ & Alto & Muitas & $\begin{array}{l}\text { Busca sistemática, } \\
\text { respeitando um } \\
\text { método, ou } \\
\text { seguindo um } \\
\text { procedimento } \\
\text { específico. }\end{array}$ \\
\hline
\end{tabular}

Fonte: adaptado de Choo (1999)..

Quadro 1 - Formas de monitoração.

\subsection{A monitoração e as demais técnicas de coleta de dados}

Frishammar (2002) salienta que todos os processos de busca de informações são orientados ao futuro, isto é, buscam sinais que possam, de alguma forma, auxiliar o gestor a antever eventos e a tomar decisões.

Ao tentar diferenciar monitoração do ambiente e as demais técnicas de coleta de dados para a organização, Choo (1999) definiu este processo como sendo o mais amplo dentre os disponíveis, aquele que procura estar atento ao maior número de estímulos possíveis. Visão compartilhada por Frishammar (2002), que aponta o Business Intelligence (BI) como um componente da monitoração do ambiente, sendo este o mais amplo conceito, quando da busca de informações. 
No entanto, não há um consenso na literatura, por vezes o BI é considerado o processo mais amplo, de acordo com Pawar e Sharda (1997), a monitoração é um componente de algo maior, o BI.

O conceito de monitoração do ambiente, aqui utilizado, é baseado na visão de Frishammar (2002) e Choo (1999) em função de dois fatores específicos: a continuidade e o foco. Enquanto a monitoração do ambiente é um processo que se desenvolve continuamente como as demais atividades da organização, o BI tem um ciclo bem definido, como uma tarefa especial, baseado num ciclo de inteligência. Já no que tange ao foco, enquanto a monitoração busca informações de qualquer natureza, as quais possam influenciar a organização, o Bl está focado em ambientes definidos, com escopo limitado, mais restrito.

Choo (1999) ainda ressalta que a monitoração do ambiente é mais ampla por compreender a análise de outros setores do ambiente externo que possam, de alguma forma, ajudar gestores a planejar o futuro da organização. Estão incluídos neste escopo: concorrentes, fornecedores, clientes, tecnologia, condições econômicas, políticas, agências reguladoras, tendências sociais e demográficas.

\subsection{As dimensões da monitoração do ambientes}

Buscando organizar os diferentes tópicos abordados na literatura, foi possível identificar cinco dimensões distintas (ANDRIOTTI e FREITAS, 2007). Cada uma delas é descrita a seguir.

\subsubsection{As fontes informais de informação}

Grande parte dos estudos realizados na área de monitoração do ambiente está voltada ao estudo do meio externo e às fontes formais de informações. Ao privilegiar essas duas características, as organizações desprezam duas fontes igualmente ou mais importantes, as fontes informais e todo o ambiente interno.

Davenport (2001) salienta que a organização que despreza seu ambiente externo terá uma vida curta, pois, desta forma, corre o risco de desperdiçar novas oportunidades e também ignorar futuras ameaças. No entanto, da mesma forma que as fontes externas, internamente a organização está sujeita a diferentes ameaças, as quais podem influenciar diretamente no desempenho organizacional, por isso mesmo atentar também ao ambiente interno é fundamental para as atividades da empresa.

As diferentes fontes de informação, formais ou informais, possuem realidades diferentes e exigem que as empresas aloquem mais ou menos recursos, de acordo com a profundidade e complexidade. A sua classificação envolve sua fonte, origem e também de acordo com o seu caráter (FREITAS et al., 1997) e considera-se informal quando a informação é transmitida por fontes pessoais ou humanas, ou, então, mesmo tramitando por canais formais, ela não tenha um caráter formal, sendo uma opinião, um comentário ou mesmo uma informação baseada em boatos, rumores, opiniões.

É importante destacar que os executivos devem estar preparados para coletar informações de fontes formais ou informais e procurar por estas dentro e fora da organização, em fontes internas e externas. E, dentre os tipos de fontes e as informações de diferentes características que foram abordadas, há uma intersecção em algum momento, isto é, através de uma fonte formal receber informações internas ou externas, e o mesmo para as fontes informais. 
Ao contrário das fontes impessoais, que são de fácil acesso, as fontes pessoais requerem mais atenção e investimento por parte das organizações e caracterizam-se por não possuírem um caráter oficial (FREITAS et al., 1997). Como não são estruturadas e estão disponíveis em grandes quantidades, muitas organizações desprezam essas fontes, ou a formalização dessas, o que não permite que elas sejam armazenadas e estejam disponíveis a outros interessados ou mesmo para um uso futuro.

Tomadores de decisão fazem uso de diferentes tipos de informação, contudo, nos níveis mais gerenciais, grande parte da informação vem de fontes pessoais, obtidas através da interação com outras pessoas (DAFT, SORMUNEN e PARKS, 1988), sendo essa a melhor fonte (AGUILAR, 1967; KEEGAN, 1974; BARBOSA, 1997, 2006; CHOO, 1999).

Myburgh (2004) traz uma série de questões que deveriam ser respondidas antes da definição daquilo que será observado, como, por exemplo: "Onde encontrarei o que estou procurando?"; "Quanto tempo irá tomar?"; "Qual será o custo aproximado?". A principal função dessas perguntas é evitar que haja uma busca excessiva de informações, especialmente a coleta de dados, que não tenham significado relevante para a empresa.

Destacando a importância desse tipo de fonte, Davenport (2001) salienta que as informações mais importantes e valiosas estão na cabeça dos executivos. Goodman (1993) e Kaye (1995b) suportam essa premissa, apontando que as fontes pessoais são mais ricas que as fontes impessoais por permitir que quem recebe a informação capte outros sinais, como expressão facial, tom da mensagem e, de acordo com a classificação de Daft e Lengel (1986, p. 560), as fontes informais, ou pessoais, são aquelas que podem prover dados com uma maior riqueza: "Mídias ricas são pessoais e envolvem contato face a face" .

Por fim, Sapiro (1993) ressalta que é fundamental saber escolher entre as diversas fontes de dados, dessa forma, a empresa poderá focar naquelas que realmente fornecem os melhores dados, possibilitando também classificá-las, o que facilita acessos posteriores e também estar constantemente avaliando a relevância de cada uma das fontes, de tal forma que o esforço esteja sempre concentrado naquelas que forem mais relevantes para o sucesso do negócio (DEGENT, 1986).

\subsubsection{Armazenamento das informações}

Uma organização que está atenta ao seu ambiente, que busca informações, precisa ter uma forma de armazenar essas informações, de armazenar o que é coletado. Muitas informações, como já foi apontado, estão somente na mente das pessoas, mas o que acontece caso esse indivíduo fique doente ou seja demitido? Precisa haver esse repositório de informações, ao qual mais pessoas tenham acesso.

De acordo com Aaker (1983), a organização pode conceber ou disponibilizar aos seus funcionários desde sistemas mais complexos, quanto mais simples de armazenamento, contanto que tenha algo que permita gravar essas informações. Conforme o autor, os gerentes e demais indivíduos estão expostos a uma grande quantidade de informações, em muitos casos estratégicas, mas que são perdidas e não utilizadas, seja por esquecimento, seja por não reconhecer a importância delas.

\subsubsection{A maneira de coletar informações}

Detectar os sinais do ambiente é semelhante ao processo de identificação de um objeto que está muito distante, no princípio não é possível distinguir o que virá; com o tempo 
e a aproximação, vai sendo possível identificar o objeto. O mesmo serve para os sinais, no princípio, como já foi salientado, é difícil diferenciar oportunidades e ameaças, e com que intensidade irá afetar a organização (ANSOFF, 1975).

A coleta, como salienta Daft e Weick (1984), é um jogo de perguntas e respostas. A organização vai para o ambiente procurando respostas às suas dúvidas e espera encontrar, no mercado, as respostas mais adequadas. Os questionamentos são diversos, tais como: O que meus clientes esperam da minha empresa?; Qual será a próxima decisão do governo sobre os juros?; Meus fornecedores manterão a política atual de preços por quanto tempo?

A forma e a profundidade com que as informações são coletadas impactam a quantidade e o custo de obtenção. De acordo com Freitas e Janissek (2006), é possível obter 100\% das informações, com $100 \%$ de custo ou, então, obter $80 \%$ das informações com apenas $20 \%$ de custo. Assim, a forma com que é feita a coleta influencia diretamente esses dois elementos, custo e amplitude. Conforme ressaltam Benamati e Lederer (2001), a forma errada de coletar pode ser muito dispendiosa, além de fornecer informações incompletas e equivocadas.

\subsubsection{A finalidade da monitoração}

A monitoração do ambiente pode servir a diferentes propósitos, de acordo com a postura de cada organização. De acordo com Choo (2001), a informação que é coletada pode servir, basicamente, a três diferentes finalidades: tomada de decisão, planejamento estratégico e redução das incertezas.

Conforme aponta Barbosa (1997, p. 42), há um longo e "complexo caminho entre a informação externa e a sua efetiva utilização pelos administradores que participam da formulação de políticas e estratégias empresariais". O mesmo ocorre com as informações internas, as quais também precisam percorrer um longo caminho até serem de fato utilizadas.

Neste sentido, Albright (2004) ressalta que a monitoração também tem por finalidade, além de toda orientação externa, estar atenta ao que ocorre no ambiente interno. Isso permite que a organização possa avaliar melhor suas forças e fraquezas, tanto internamente, podendo ajustar operações para enfrentar novos desafios, quanto externamente, analisando competidores, novos mercados, novas tecnologias.

Pode-se afirmar, ainda, que as informações são coletadas com outras finalidades. Após tomar qualquer decisão, é necessário supervisionar os resultados, que, de certa forma, faz parte do processo decisório, mas coletada com finalidade distinta. Além de reduzir incertezas e evitar ameaças, as informações podem ser coletadas no intuito de buscar oportunidades no ambiente, ou seja, outra forma de monitorar o mercado.

Kaye (1995b), ao estudar a importância das informações para executivos e gestores para organizações que querem se manter competitivas no mercado, apontou algumas finalidades para a informação que é coletada por meio de mecanismos, processos, como a monitoração ambiental: treinamento, ensino, aprendizagem, resolução de problemas, tomada de decisão, criação de imagem, influenciar ou manipular, dominação e subordinação, entre outras finalidades.

\subsubsection{Disponibilizando, explorando e disseminando as informações}

O grande desafio de qualquer atividade organizacional está em lidar com as incertezas do mercado. Muitas vezes, as decisões tomadas são para um determinado cenário, o qual está constantemente mudando. As informações, como salienta Ansoff (1975), por vezes não estão 
disponíveis no momento adequado, isto é, não permitem que a organização prepare planos e programas já adequados a elas.

Os planos e programas, com ou sem as informações adequadas, são elaborados para serem executados. Caso as informações não sejam adequadas, não se pode esperar que as ações tenham os resultados esperados. Para que o impacto das decisões seja positivo, essas informações devem ser basear-se em dados consistentes, atuais e adequados à realidade da organização.

Além de armazenar o resultado da monitoração do ambiente, informação, éfundamental que outras pessoas tenham acesso e possam também contribuir. Conforme salienta Albright (2004), o benefício está justamente em evitar não só o retrabalho de coletar novamente essas informações, como também diminuir a ambigüidade do que está disponibilizado.

O simples fato de possuir um local específico para armazenar essas informações não garante um diferencial à organização. Além de permitir que diferentes indivíduos participem do processo de coleta, esse ambiente deve permitir que outras pessoas tenham acesso e ele deve ser divulgado entre os demais colaboradores, sendo, assim, mais um recurso, principalmente na tomada de decisão.

É fundamental que as organizações busquem identificar quais fontes são as mais apropriadas para os objetivos e estratégias, contudo, é no processo de análise que as informações irão adquirir valor para os executivos. Para Choo (2005), as organizações buscam interpretar as informações para dar sentido sobre os dados da própria empresa, procurando entender o que a organização está fazendo e o que pode acontecer no futuro.

De acordo com Goodrich (1987), o processo de avaliação e interpretação de tudo que foi coletado segue alguns passos básicos:

- avaliar a significância de cada item selecionado para a organização;

- identificar padrões que parecem, por meio da análise de grupos de itens, estar se desenvolvendo no ambiente;

- interpretar o que podem significar esses padrões de eventos e tendências;

- desenvolver hipóteses sobre as conseqüências potenciais desses eventos/tendências para a organização;

- descobrir outros sinais no ambiente, que podem ou não confirmar esses padrões e sua significância para a organização;

- purgar o sistema dos sinais falsos e hipóteses desacreditadas.

É de suma importância que cada etapa do processo seja supervisionada, para garantir a eficiência, não permitindo que "vícios" se estabeleçam e que possam vir a, eventualmente, comprometer todo o processo. Processo porque esta atividade deve ser constante, buscando sempre que a organização adquira ou mantenha a sua vantagem frente aos demais concorrentes. A cada reação da organização, uma nova realidade organizacional estará sendo criada, exigindo que outras fontes ou outras informações sejam adquiridas.

Nessa busca por sinais do ambiente, Blanco e Lesca (1997) alertam que o ambiente pode emitir dois tipos diferentes de sinais: (a) aqueles que indicam mudanças futuras claras e (b) aqueles sobre fatores externos que possam gerar mudanças nas condições atuais.

O processo de interpretação dos dados é exclusivamente dependente das pessoas que participam do processo, por isso mesmo está suscetível a fatores tanto internos quanto externos que podem prejudicar ou, então, influenciar a atividade.

Quando a monitoração do ambiente é feita de modo consciente, isto é, quando se busca algo específico, com um propósito, a questão relevância terá menos impacto, pois o que se busca será utilizado. Quando, no entanto, a busca é indireta, alguns dados podem não ter 
sua relevância reconhecida, devido a dois fatores basicamente: (a) falta de informação interna de quem está coletando, isto é, não estando alinhado com a organização o profissional pode desconsiderar informações importantes, e (b) a habilidade para reconhecer a informação, ou seja, não estar familiarizado com o que está sendo observado.

Outro fator que pode influenciar a relevância é a linguagem em que os dados são coletados. Especialmente com a Internet, informações de diferentes locais do mundo estão disponíveis e, muitas vezes, há barreiras quanto ao idioma, costumes locais, gírias, para citar algumas características. Acrescenta-se a isso pressão por tempo, o que impede, muitas vezes, que outros dados sejam coletados, dados novos ou que confirmem aquilo que já tenha sido coletado, e também a motivação de quem está envolvido na atividade, o que influenciará com que atenção os dados serão analisados.

Afora a relevância, ainda há a possibilidade de a informação ter seu significado distorcido dentro da organização, de forma intencional ou não, mas que pode ter conseqüências para o tomador de decisão.

No processo de análise das informações, é de vital importância que não apenas uma pessoa participe (CARON-FASAN e JANISSEK-MUNIZ, 2004; JANISSEK-MUNIZ, LESCA e FREITAS, 2006), mas sim outras tantas que forem habilitadas para tal, de diferentes áreas, todos trabalhando em cima da mesma informação, e não como se fosse uma linha de produção, em que cada um cuida de uma parte. Dessa forma, garante-se que cada dado seja analisado sob diferentes pontos de vista, visão compartilhada por Goodrich (1987), que aponta a diversidade de opiniões como principal fonte de riqueza para a análise.

Neste artigo, foram analisadas somente duas dimensões específicas, quais sejam: a escolha das fontes e a posterior análise e disseminação das informações.

\section{Método de pesquisa}

Para realizar a pesquisa, optou-se por um estudo exploratório, de cunho qualitativo. Depois de uma primeira fase mais teórica, apresentada na seção 2, foi possível identificar as cinco dimensões de monitoração do ambiente. Na segunda fase, de coleta de dados, foram selecionados e entrevistados alguns executivos. As análises tiveram como foco as informações informais na atividade de monitoração do ambiente.

\subsection{Elaboração do roteiro}

A realização de entrevistas é um método de pesquisa qualitativa, o qual visa a compreender um fenômeno do ponto de vista dos participantes e seu contexto (POZZEBON e FREITAS, 1998) e pode ser classificada de três formas distintas (GODOI e MATTOS, 2006; FRANKFORT-NACHMIAS e NACHMIAS, 1996): conversacional livre/não-estruturada, baseada em roteiro/estruturadas, padronizada aberta/focada. Para esta pesquisa, as entrevistas foram do tipo focada, isto é, com um tema bem definido e um instrumento padrão a todos os respondentes.

O instrumento contou com diferentes questões que buscavam analisar cada uma das dimensões identificadas na fase de revisão da literatura. Como auxílio no processo de coleta, cada questão teve seu objetivo definido, o que permitiu uma melhor condução das entrevistas. Para validar o instrumento utilizado, este foi submetido à apreciação de um professor doutor e de um doutorando, ambos com experiência no desenvolvimento de instrumentos e também com amplo conhecimento no tema. 


\subsection{Entrevista com executivos}

O principal critério de seleção das empresas e, por conseguinte, dos executivos, foi a atuação na área de TI. Em segundo lugar, foi a localização, ou seja, que tivessem suas atividades voltadas para o mercado de TI do Rio Grande do Sul.

Assim como em outras áreas, a quantidade de empresas que atuam nesse mercado é muito grande. Por conveniência e facilidade de acesso, chegou-se a uma lista de sete empresas distintas, reconhecidas em suas áreas de atuação dentro do mercado de TI, e foi possível realizar o estudo junto a quatro delas.

Desse total de quatro empresas, em uma, do setor público, um dos executivos entrevistados (EXECUTIVO 2) sugeriu e facilitou o contato com um segundo executivo (EXECUTIVO 3). Por essa razão, apesar de serem quatro organizações, obteve-se cinco entrevistas.

\subsection{Análise dos resultados}

Apesar de o instrumento abordar todas as dimensões da monitoração do ambiente identificadas na seção 2, somente duas foram analisadas para fins deste artigo.

\section{Análise dos resultados}

Os dados coletados durante a entrevista foram analisados conforme duas das dimensões identificadas na literatura: as fontes informais de informação e de que forma os executivos exploram e disseminam essas informações. A seguir, cada uma dessas dimensões é apresentada e analisada.

\subsection{Fontes informais de informação}

A escolha correta das fontes que são utilizadas é muito importante. De acordo com diversos autores, ela interfere na riqueza e objetividade das informações coletadas, as quais podem ser de caráter mais formal ou mais informal.

De acordo com os entrevistados, são utilizadas fontes diferentes, até mesmo para permitir outras visões sobre um mesmo assunto. Dessa forma, cada informação coletada pode ser confrontada por mais de uma fonte, o que permite confrontar, confirmar ou trazer mais subsídios para o gerente e também para o jornalista.

Os executivos buscam ter na sua base de relacionamentos pessoas que possam contribuir, opinar, sugerir melhorias nos produtos ou até mesmo sugerir algo novo, de vanguarda no mercado.

[...] em eventos, a gente troca cartão, conhece a pessoa, almoça com ela, discute, apresenta os produtos e pergunta a opinião dela... Às vezes ela diz para esperar ou, então, que não dá, que não é por aí (EXECUTIVO 1).

[...] aí eu fui e conversei com ele [cliente] sobre o que ele achava se a gente desenvolvesse uma solução... Eles gostaram da idéia, conversaram com o restante da rede, sugerindo a tal solução (EXECUTIVO 5).

[...] quando tenho algo pronto, vamos para a rua mostrar pros caras... Vamos até um cliente e 
damos duas notícias para a pessoa lá: a primeira é que tu vai receber de graça esse produto, a segunda é que tu vai me dizer quanto pagaria por isso aqui (EXECUTIVO 4).

Apesar de reconhecer a importância desses relacionamentos informais para a organização, nenhuma decisão é baseada única e exclusivamente nesses dados. As fontes formais complementam, dando outros sinais do mercado, mais objetivos, como crescimento, dados históricos, e acabam complementando as informações informais (ou vice-versa) e dando suporte à tomada de decisão.

[...] a informação informal traz muitos riscos... Pode influenciar a decisão de investir em algo que não trará retorno... A decisão é baseada em bases analíticas... Que apresentam o movimento do mercado (EXECUTIVO 1).

[...] tem muito sinal errado no mercado, a gente tem que tomar cuidado... Pegamos também alguns indicadores que a gente consegue na mídia (EXECUTIVO 4).

[...] tu obtém uma informação informal nos corredores, daí tem todo o trabalho de checar a informação, buscar fontes oficiais justamente para corroborar o que foi dito... Existe uma preocupação em avaliar se aquilo tem fundamento ou se é apenas um boato (EXECUTIVO 2).

Todas as entrevistas tiveram como ponto em comum o excesso de informações que são recebidas todos os dias, das mais diferentes fontes, formais ou informais. De acordo com Cohen (2002, p. 27), "o mundo passa pelo problema de se ter muitas informações, significando uma sobrecarga", o que dificulta o trabalho de coleta e seleção de informações úteis no ambiente.

Esse excesso prejudica a localização ou extração das informações que realmente irão trazer uma vantagem competitiva em relação aos seus concorrentes. Como saída, todos apontaram, de forma direta ou indireta, que recorrem a fontes informais, como amigos, outros profissionais, clientes, colegas de trabalho, para buscar as informações com mais valor.

Essa escolha pelas fontes mais informais corrobora outros estudos já realizados nessa área (KEEGAN, 1974; DEGENT, 1986; AUSTER e CHOO, 1994; BARBOSA, 1997; CHOO, 1999; ALBRIGHT, 2004, entre outros), os quais apontam que contatos feitos face a face, sem um caráter formal, facilitam o processo de monitoração, pois permitem o acesso rápido às informações.

Quanto a essas fontes de informações informais, chama a atenção que nenhuma das empresas utiliza a academia (universidades, centros de excelência, núcleos de pesquisa, entre outros) como uma fonte. Centros de pesquisa, que poderiam fornecer dados sobre novos produtos ou pesquisas que indicassem alguma demanda específica ou mesmo novas formas de realizar determinada tarefa e que poderia impactar a maneira pela qual os produtos são desenvolvidos, não são citados como um fontes de informação relevantes.

Durante as entrevistas com os executivos, ficou clara a importância em se ter clienteschave, os quais podem testar novos produtos, sugerir melhorias e mesmo inovações dentro do mercado. Apenas o EXECUTIVO 2 não citou os clientes, acredita-se que seja em função do cargo que ocupa e do tipo de atividade que desenvolve dentro da empresa.

O EXECUTIVO 4 foi o único que citou a questão da percepção, intuição, como sendo uma fonte de informação. Ele cita um caso em especial, no qual, olhando o mercado e através de conversas, teve o reflexo de desenvolver algo inovador. 
Também foi ressaltada a importância de estar presente em eventos dos mais diversos possíveis, como conferências, almoços de entidade, nos quais seja possível entrar em contato com públicos diferentes. Nessas ocasiões, estão oportunidades de falar, informalmente, com concorrentes, distribuidores, membros de entidades, os quais podem fornecer informações que podem auxiliar na definição de novas estratégias e produtos. Assim, há a formação de uma rede de contatos, os quais podem ser acionados em momentos futuros, via encontros formais ou informais.

Apesar de todos terem ressaltado a importância das fontes informais no processo de monitoração do ambiente, quando questionados acerca da confiabilidade de uma lista de fontes que foi apresentada, as menores notas foram atribuídas às fontes informais. Esse fato retrata a preocupação com as informações que essas fontes podem fornecer e pode ser explicado pelo esforço que é realizado no sentido de buscar sempre checar, mediante fontes mais formais, o que vem de fontes informais.

As principais fontes podem ser observadas no Quadro 2.

\begin{tabular}{|c|l|}
\hline \multicolumn{1}{|c|}{ QUEM } & \multicolumn{1}{|c|}{ FONTES DE INFORMAÇÕES INFORMAIS CITADAS } \\
\hline EXECUTIVO 1 & $\begin{array}{l}\text { Clientes, formad ores de opinião, gru pos de discussão, outros profis sio nais, } \\
\text { concorrentes. }\end{array}$ \\
\hline EXECUTIVO 2 & Colegas de trabalho, profissionais do mercador de TI, colegas de profissão. \\
\hline EXECUTIVO 3 & $\begin{array}{l}\text { Diretores, colegas de trabalho, pessoas de outras empresas, amigo s, clientes, } \\
\text { parceiros de comercialização. }\end{array}$ \\
\hline EXECUTIVO 4 & $\begin{array}{l}\text { Clientes, colegas de trabalho, concorrentes, distribuidores, outras subsidiárias, } \\
\text { percepção. }\end{array}$ \\
\hline EXECUTIVO 5 & Colegas de trabalho, clientes, matriz. \\
\hline
\end{tabular}

Quadro 2 - Fontes informais

\subsection{Exploração e disseminação da informação informal}

Tendo coletado as informações necessárias, é importante que exista a fase de exploração, ou seja, de dar um sentido às informações, como uma espécie de tradução das idéias em possíveis ações. Esse planejamento, essa formulação de estratégias, como salientam alguns autores (CARON-FASAN e JANISSEK-MUNIZ, 2004; JANISSEK-MUNIZ, LESCA e FREITAS, 2006), deve ser feita de modo a contemplar diferentes visões e opiniões.

A diversidade de opiniões ou de visões sobre um mesmo assunto permite que diferentes concepções de mundo sejam contempladas. Segundo Moresi e Tarapanoff $(2002$, p. 5) "cada pessoa é feita da inteligência de diferenças, de comportamentos, de acontecimentos que se reconstroem em cada um, como um efeito da interpretação", e completa que todos devem ter a humildade de reconhecer que nenhuma visão é completa.

Com base nas entrevistas feitas com os executivos, foi possível detectar uma espécie de seqüência, com algumas etapas que podem ocorrer durante essa etapa de exploração. Ao submeter as informações para que outros indivíduos tenham acesso, isso ocorre (a) internamente, ou seja, com colegas de trabalho, diretoria ou equipe de vendas, (b) com clientes-chave, lançando a idéia para apreciação e coletando sugestões. 
[...] (a) a gente trabalha numa reunião de diretoria... (b) contato direto com o cliente (EXECUTIVO 1).

[...] (a) a gente gosta de ver a opinião dos colegas (EXECUTIVO 2).

[...] (a) reunião com um comitê... (b) consulta o cliente (EXECUTIVO 3).

[...] (a) mostro a idéia com o pessoal aqui... (b) mostrei o rabisco para a empresa X (EXECUTIVO

4).

[...] (a) converso com as pessoas que trabalham comigo... (b) temos um cliente... aí eu fui e conversei com ele da idéia (EXECUTIVO 5).

Esta etapa de contato com o cliente funciona como uma espécie de prototipação, na qual é feita uma maquete funcional do produto a ser desenvolvido e, então, é implantando para testes. Como um dos entrevistados ressalta, o produto, inicialmente, está "banguela e careca" (EXECUTIVO 4), no sentido de não estar pronto para ser lançado ao mercado, mas possível de ser posto à prova.

Após esta fase de apreciação por algum cliente-chave há, uma nova etapa, interna, de exploração das informações para avaliar o processo e viabilidade do projeto e também para contemplar as sugestões que foram dadas. Além disso, o cliente ainda pode contribuir dizendo o justo preço do produto no mercado em relação a outras soluções que, eventualmente, possam estar disponíveis.

Além das etapas que foram apresentadas, um dos entrevistados ainda comentou a possibilidade de expor ou comentar informalmente uma idéia de produto com outros fornecedores, até mesmo concorrentes, para, de certa forma, buscar subsídios na tentativa de sondar o mercado e melhorar o produto, por meio de encontros em feiras, congressos e encontros informais.

Outro ponto importante que transpareceu nas entrevistas com os executivos foi a presença de alguém ou um grupo para discutir, trocar idéias. Como uma fase de amadurecimento, cada projeto é discutido internamente, principalmente com alguém que tenha vasta experiência no mercado ou algum colega que possa contribuir com outro ponto de vista. Foram citadas, principalmente, as pessoas que têm algum tipo de contato comercial e não técnico, o que demonstra o interesse de aproximar o produto daquilo que o mercado necessita, e não apenas uma visão técnica.

Essas interações favorecem a divulgação das informações que foram coletadas. Conforme ressalta Degent (1986), o que circula nessas reuniões não deve se restringir ao ambiente externo, mas sim compreender aquilo que circula e é coletado no ambiente interno, de maneira a manter todos os executivos informados sobre o que está ocorrendo.

Como instrumento para essa espécie de brainstorming, foi citada principalmente a convocação de reuniões nas quais colegas das diferentes áreas participam, incluindo pessoal da área técnica, para discutir e amadurecer idéias e explorar as informações que foram coletadas. Em alguns casos, o resultado dessas reuniões é armazenado para uso futuro; em outros, serve apenas para informar a todos do que se passa no mercado.

[...] a gente trabalha numa reunião de diretoria [...] isso não vai formalmente em nenhum lugar

[...] quem se sente influenciado por essas informações vai atrás (EXECUTIVO 1). 
[...] a gente tem a possibilidade de identificar nesse sistema que a gente registra [...] se foi uma reunião, uma ata, uma visita (EXECUTIVO 3).

[...] chama reunião, documenta, faz uma ata, monta o projeto, designa quem é o responsável, como se fosse projeto do cliente (EXECUTIVO 4).

Outro ponto levantado pelos entrevistados foi a questão do acesso à informação. Os três entrevistados que afirmaram registrar em um sistema aquilo que recebem, apontaram também a questão dos níveis de acesso. Muitas vezes, o que é armazenado transcende a própria informação, é o resultado de debates e estudos, os quais não podem ficar liberados para que todos visualizem.

[...] a gente pode marcar se aquela informação é pública ou restrita e lá embaixo a gente seleciona quais são as pessoas que têm acesso àquela informação (EXECUTIVO 3).

[...] qualquer pessoa que eu der acesso ao sistema (EXECUTIVO 5).

Apesar de estar ciente dessa questão, um entrevistado afirmou não se preocupar com o que está aberto e com o que está restrito, pois mesmo que alguém acesse alguma informação que supostamente não deveria, esta pessoa não compreenderia o que está registrado: "[...] o acesso à informação não é escalonado, qualquer pessoa tem acesso" (EXECUTIVO 4).

A informação que circula nos diferentes ambientes que envolvem a organização, interno e externo, vem imbuída de certos valores, certas visões. Nesse sentido, em todas as entrevistas, ficou clara a preocupação de divulgar ou fazer uso de algo tendencioso, especialmente quando esta informação é informal. Por não ter uma fonte oficial, um caráter formal, esta informação é vista com desconfiança, forçando com que ela seja comprovada por fontes mais formais: "[...] a coisa de difundir, divulgar a informação eu tenho um cuidado muito maior justamente para evitar ficar transmitindo algo que pode não ser verdade" (EXECUTIVO 2).

Como ressaltam diversos autores, há vários sinais disponíveis no mercado, cabe às organizações detectar e selecionar aqueles que são verdadeiros e que podem, efetivamente, contribuir para as diferentes atividades daqueles que não têm um valor para a organização e que podem vir a prejudicá-la.

\section{Considerações finais}

Quando questionados acerca da seleção das fontes, há um esforço de se ter um rol de contatos que sejam de confiança e que possam trazer informações relevantes para a organização, ou seja, de possuir fontes de caráter menos formal para a troca de informações. Como já apontado por outros estudos (KAYE, 1995b; ALBRIGHT, 2004; BARBOSA, 1997, 2006), isso permite que as informações sejam acessadas mais rapidamente.

Uma das fontes mais citadas pelos executivos foram os próprios clientes dessas organizações, os quais são ativados toda vez que há um novo projeto em desenvolvimento, isto permite que a organização aproxime o novo produto das reais necessidades de seu mercado. Nas entrevistas, fica bem clara essa preocupação, chegando ao limite, citado por um entrevistado, 
de instalar, gratuitamente, uma versão para determinado cliente para uma fase de testes.

A presença de um colega de trabalho, tanto para executivos quanto para especialistas, também obteve destaque, tanto pela facilidade de acesso quanto pelo nível de conhecimento. Ter, num mesmo ambiente de trabalho pessoas que tenham conhecimentos distintos e que possam contribuir com diferentes opiniões é algo fundamental. Conforme Aguilar (1967), muitas oportunidades aparecem dentro das organizações, onde há fontes de grande valor.

Dado que uma das principais formas de exploração e disseminação das informações coletadas é a realização de reuniões, é importante que exista esse local de armazenamento comum. Esta prática auxilia no momento em que for necessário reunir as informações que serão debatidas, e facilita todo o processo de disseminação do resultado dessas discussões.

Sobre a fase de exploração, houve unanimidade de opinião quanto à necessidade de haver uma diversidade de opiniões. Todos os entrevistados citaram a importância de discutir com colegas, clientes ou fornecedores algum projeto que esteja em desenvolvimento ou mesmo sobre a linha de produtos já em venda da organização.

Vê-se como muito positiva essa atitude de aproximar o cliente da empresa. Por meio de uma relação que extrapola aquela meramente comercial, dois dos entrevistados citaram que discutem os projetos com clientes específicos antes de lançar algo no mercado, chegando ao extremo de instalar, gratuitamente, uma versão preliminar. Isso aproxima a empresa do seu ambiente, ou seja, de seus clientes.

Mostrou-se também recorrente a presença de uma pessoa-chave dentro da organização, com a qual seja possível discutir e debater o que está em curso no ambiente. Esta pessoa, que tem formação comercial e que também pode opinar tecnicamente, contribui em diferentes momentos do dia, no ritmo em que os fatos forem ocorrendo, por meio de reuniões, formais ou informais.

Há toda uma preocupação nessa fase de exploração e disseminação com a veracidade das informações que estão sendo utilizadas e que serão repassadas. Isso tudo em função do grande volume de sinais errados que são captados junto ao ambiente, os quais podem ser "criados" para gerar uma reação por parte das organizações. Mesmo internamente, as informações precisam ser avaliadas, pois podem acabar acarretando algum movimento desnecessário. 


\section{Referências}

AAKER, D. A. Organizing a strategic information scanning system. California Management Review, v. 25, n. 2, p.76-83, Jan. 1983.

AGUILAR, F. J. Scanning the business environment. New York: Macmillan, 1967.

ALBRIGHT, K. S. Environmental scanning: radar for success. Information Management Journal, v. 38, n. 3, p.38-45, Mai./Jun. 2004.

ANDRIOTTI, F. K. ; FREITAS, H. Proposição de um estudo sobre informações informais na monitoração do ambiente organizacional. In: CONGRESSO INTERNACIONAL DE GESTÃO DA TECNOLOGIA E SISTEMAS DE INFORMAÇÃO, 4., 2007, São Paulo. Resumos e Anais dos trabalhos... São Paulo: TECSI EAC FEA USP, 2007. CD-ROM.

ANSOFF, I. H. Managing strategic surprise by response to weak signals. California Management Review, v.18, n. 2, p. 21-33, Winter 1975.

AUSTER, E.; CHOO, C. W. CEOs, information, and decision making: scanning the environment for strategic advantage. Library Trends, v. 43, n. 2, p.206-225, Fall 1994.

BARBOSA, R. R. Monitoração ambiental: uma visão interdisciplinar. RAUSP, v. 32, n. 4, p. 4253, out./dez. 1997.

. Uso de fontes de informação para a inteligência competitiva: um estudo da influência do porte das empresas sobre o comportamento informacional. Revista Eletrônica DAFT, R. L.; SORMUNEN, J.; PARKS, D. Chief de Biblioteconomia e Ciência da Informação, ed. executive scanning, environmental characteristics, esp., p.91-102, 10 Semestre, 2006. BENAMATI, J.; LEDERER, A. L. Rapid information Strategic Management Journal, v.9, n.2, p.123-139, technology change, coping mechanisms, and the emerging technologies group. Journal of Management Information Systems, v.17, n.4, p.183-202, Spring 2001.

BLANCO, S.; LESCA, H. Environmental scanning: p.554-571, May 1986. designing a collective learning process to track down weak signals. In: ASSOCIATION FOR INFORMATION SYSTEMS, 3., 1997, USA. and company performance: an empirical study.

Anais... Conference of AIS, USA1997. p.82-83.

CARON-FASAN, M-L; JANISSEK-MUNIZ, R.

Análise de informações de inteligência estratégica antecipativa: proposição de um método, caso aplicado e experiências. RAUSP, v.39, n.3, p.205-219, jul./set. 2004.

$\mathrm{CHOO}, \mathrm{C} . \mathrm{W}$. The art of scanning the environment. Bulletin of the American Society for Information Science, v.25, n.3, p.21-24, Feb./Mar. 1999.

. Environmental scanning as information

seeking and organizational learning. Information Research, v.7, n.1, Sept. 2001. Disponível em: < http://nformationR.net/ir/7-1/paper112.html>. Acesso em: 20 maio 2007.

The knowing organization: how organizations use information to construct meaning, create knowledge, and make decisions. Oxford University Press: USA, 2005.

COHEN, M. F. Alguns aspectos do uso da informação na economia da informação. Ciência da Informação, Brasília, v. 31, n. 3, p. 26-36, set./dez. 2002.

COSTA, J. An empirically-based review of the concept of environmental scanning. International Journal of Contemporary Hospitality Management, v.7, n.7, p.4-9, 1995.

DAVENPORT, T. H. Ecologia da informação. São Paulo: Futura, 2001.

DAFT, R. L.; WEICK, K. E. Toward a model of organizations as Interpretation systems. The Academy of Management Review, v.9, n.2, p.284-295, Apr. 1984. Mar./Apr.1988.

DAFT, R. L.; LENGEL, R. H. Organizational information requirements, media richness and structural design. Management Science, v.32, n.5, DEGENT, R. J. A importância estratégica e o funcionamento do serviço de inteligência empresarial. RAE, v.26, n.1, p.77-83, jan./mar. 1986. 
DRUCKER, P. F. A decisão eficaz. In: HBR: Processo decisório: os melhores artigos da Harvard Business Review. São Paulo: Campus, p. 9-26, 2006.

FRANKFORT-NACHMIAS, C.; NACHMIAS, D. Research methods in the social sciences. 5. ed. Nova lorque: St. Martin's, 1996.

FREITAS, H.; BECKER, J. L.; KLADIS, C. M.; HOPPEN, N. Informação e decisão: sistemas de apoio e seu impacto. Porto Alegre: Ortiz, 1997.

FREITAS, H.; JANISSEK-MUNIZ, R. Uma proposta de plataforma para inteligência estratégica. In: CONGRESSO IBERO-AMERICANO DE GESTÃO DO CONHECIMENTO E INTELIGÊNCIA COMPETITIVA, I GeCIC, 2006, Curitiba. Anais.. Curitiba: ABRAIC, 2006. CD-ROM.

FRISHAMMAR, J. Characteristics in information processing approaches. International Journal of Information Management, v.22, p.143-156, 2002.

GODOI, C. K.; MATTOS, P. L. C. L. de. Entrevista qualitativa: instrumento de pesquisa e evento dialógico. In: GODOI, C. K.; MELO, R. B. de; BARBOSA, A. Pesquisa qualitativa em estudos organizacionais: paradigmas, estratégias e métodos. São Paulo: Saraiva, 2006. p. 301 323.

GOODMAN, S. K. Information needs for management decision-making. ARMA Records Management Quartely, v.27, n.4, p.12-23, Oct. 1993.

GOODRICH, R. S. Monitoração do ambiente externo: uma necessidade para as organizações tecnológicas. RAE, v.27, n.1, p.5-10, jan./mar. 1987.

JANISSEK-MUNIZ, R.; LESCA, H.; FREITAS, H. Inteligência estratégica antecipativa e coletiva para tomada de decisão. In: CONGRESSO INTERNACIONAL DE GESTÃO DA TECNOLOGIA E SISTEMAS DE INFORMAÇÃO (CONTECSI), 3., 2006, São Paulo. Resumos e Anais dos trabalhos... São Paulo: FEA/USP, 2006.

\section{p. 242, CD-ROM.}

KAYE, D. Sources of information, formal and informal. Management Decision, v.33, n.5, p.13-15, 1995 a. . Importance of information. Management Decision, v.33, n.5, p.13-15, 1995 b.

KEEGAN, W. J. Multinational scanning: a study of the information sources utilized by headquarters executives in multinational companies. Administrative Science Quarterly, v.19, p.411-421, 1974.

MORESI, E. A. D.; TARAPANOFF, K. M. A.

Monitoração ambiental e percepção da realidade. In: ISKM, 4., 2002, Curitiba. Anais...Curitiba, 2002. CD-ROM

MYBURGH, S. Competitive intelligence: bridging organizational boundaries. Information Management Journal, v.38, n.2, p.46-55, Mar./Apr. 2004.

PAWAR, B. S.; SHARDA, R. Obtaining business intelligence on the internet. Long Range Planning, v.30, n.1, p.110-121, 1997.

PORTER, M.E. Estratégia competitiva: técnicas para análise de indústrias e da concorrência. 7. ed. Rio de Janeiro: Campus, 1986.

POZZEBON, M.; FREITAS, H. Modelagem de casos: uma nova abordagem em análise qualitativa de dados? In: ENANPAD, 22., 1998, Foz do Iguaçu. Anais... Foz do Iguaçu: ANPAD, 1998. CD-ROM. Administração da Informação.

SAPIRO, A. Inteligência empresarial: a revolução informacional da ação competitiva. RAE, v. 33, n.3, p.106-112, maio/jun. 1993. 